\title{
OUTCOME OF SCLEROTHERAPY IN THETREATMENT OF NON-HEALING VARICOSE ULCERS UNDER ULTRASOUND CONTROL
}

\author{
Muhammad Jamila, Rashid Usman ${ }^{\mathrm{b}}$, Aaiza Amanc, Kishwar Alid, Rai Ahmad Khan Kharle \\ aProfessor \& Head Department of Vascular Surgery, Combined Military Hospital Rawalpindi. \\ ${ }^{b}$ Assistant Professor, Department of Surgery Combined Military Hospital Lahore Medical College \\ Lahore. \\ cHouse officer Fauji Foundation Hospital Rawalpindi. \\ ${ }^{\mathrm{d} A s s i s t a n t}$ Professor Department of Surgery/ Consultant Vascular Surgeon,Fauji Foundation Hospital \\ Rawalpindi. \\ eConsultant Vascular Surgeon Armed Forces Hospital, Taif Saudi Arabia.
}

\begin{abstract}
:
BACKGROUND \& OBJECTIVE: Varicose veins are the commonest vascular problem both in men and women worldwide. Lack of timely management, inadequate treatment, and maltreatmentof varicose veins can lead to the development of nonhealing ulcers and affects the quality of life in terms of health. Surgery, heat therapy, chemical therapy, and endoscopic treatment are the options of treatment. Foam sclerotherapy is relatively a new technique being practiced all over the world and has promisingresults. The objective was to determine the outcomes of foam sclerotherapyin thetreatment of non-healing varicose ulcers.
\end{abstract}

METHODOLOGY: In this descriptive study, 240 patients withchronic leg ulcers with varicose veins had been managed with foam sclerotherapy under ultrasound and compression bandage. All patients were reviewed at 7 days, 1month, 3 months, 6 months, 1 year, and 18 months both clinically and radiologically with a doppler ultrasound to assess the ulcer healing rates.

RESULTS: The overall healing after 04 weeks of foam sclerotherapywas $83 \%$. Two hundred and twenty-nine patients (95.4\%) withulcers healed within 02 months of the start of ultrasound-guided foam sclerotherapy. Delayed healing occurred after four months in 11 cases. All those cases had either previous varicose veins surgery or deep vein thrombosis,orextensive perforator disease. During 18 months of follow-up, seven patients showed recurrencewith a mean symptom-free period of07 months.

CONCLUSION: Chronic venous ulcers treated with foam sclerotherapyunder ultrasound guidance are associated with a high healing rate and low recurrence rate.

KEYWORDS: Chronic, Foam sclerotherapy, Treatment, Venous ulcer.

How to cite this:

doi: https://doi.org/10.37723/jumdc.v12i2.424

Jamil M, Usman R, Aman A, Kharl Khan RA. OUTCOME OF SCLEROTHERAPY IN THE TREATMENT OF NON-HEALING VARICOSE ULCERS UNDER ULTRASOUND CONTROL. jumdc. $2021 ; 12(2): 140-145$.

doi: https://doi.org/10.37723/jumdc.v12i2.424

This is an Open Access article distributed under the terms of the Creative Commons Attribution License (http://creativecommons.org/licenses/by/4.0), which permits unrestricted use, distribution, and reproduction in any medium provided the original work is properly cited. 


\section{INTRODUCTION:}

The varicose veins are common worldwide both in men (5-15\%) and women (3-29\%) and can lead tovenous insufficiency ${ }^{[1]}$ and venous ulceration ${ }^{[2]}$ if they remain untreated. The venous insufficiency leads to ambulatory venous pressure in the affected limb, which affects the microcirculation of the skin and hence causes venous ulceration ${ }^{[3]}$. One percent of the adult European populationis affected with chronic venous ulcers, and $0.1 \%$ of people haveactive venous ulcers at any one time ${ }^{[4]}$ and adversely affects the living style ${ }^{[5]}$. Traditionally varicoseveinsare managed by surgery (flush ligation,multiple phlebectomies, stab avulsions, and stripping)and stockings. Radiofrequency ablation (RFA), endovenouslaser ablation (EVLA), and ultrasound-guided foam sclerotherapy (UGFS) currently very popular in the treatment of varicose veins and its complications.

Ultrasound-guided foam sclerotherapy is relatively safer, highly attractive, and efficient among all the interventions, especially inpatients not fit for anesthesia[ ${ }^{[6]}$. Our study assessed thehealing and recurrence ratein nonhealing varicose ulcerstreated by UGFS.

Corresponding Author:

Dr. Muhammad Jamil

Professor \& Head Department of Vascular

Surgery, Combined Military Hospital

Rawalpindi.

Email: jamilmalik13@yahoo.com

\section{METHODOLOGY:}

An ethical approval letter (Ser. No. 68/14/05/20) was taken from the ethical review committee of Combined Military Hospital Rawalpindifor this prospective observational study prior to the study. A total of 240 consecutive patients with non-purposive sampling technique, havingnonhealingulcersandmanaged by foam sclerotherapy under ultrasound control and compressionbetween September 01, 2018, and 29 February 2020, were included. The Statistical analysis was done with SPSS Version 17.0 (SPSS $($ Inc., IL, USA). The numerical variables were expressed as Means and Standard Deviations
(SD), and categorical data were expressed as Frequency and Percentage. Patients were divided into two groups, and the characteristics such as demographics, ulcer healing, and sclerotherapy sessions were compared. Groups were compared using the students' T-test, and the p-value was considered statistically significant if $p<0.05$.

Patients diagnosed with deep vein thrombosis and chronic arterial limb ischemia were excluded. The foam was made by mixing sodium tetradecylsulphate( $3 \%$ for truncal veinsand $1 \%$ for smaller veins) with air as one $\mathrm{ml}$ of sclerosant and four $\mathrm{ml}$ of air. The foam was then injected into the affected vein under ultrasound control, followed by a compression bandage.PostprocedureInj. Heparinwas given subcutaneously (5000I.u) for 03 daysalong with Tab. Augmentin $625 \mathrm{mg}$ thrice a day and Diclofenac potassium $50 \mathrm{mg}$ twice a day for 05 days. First follow-up was done after 7 days inthe clinic and the leg was assessed both clinically and with Duplex Ultrasound for occlusion of varicosities and presence of any complication. Second, third and fourth sessions were performed for residual or new varicosities. The primary endpoint of the study was healing of the ulcer and compression was continued for 3 months after healing was complete. Secondary endpoints were the requirement of subsequent sessions of sclerotherapy.

\section{RESULTS:}

Demographic data of 240 patients with active chronic venous ulcers were recorded (Table-I). Mean age was 34 years. There were $48.3 \%$ $(n=116)$ males with a male to female ratio of $1: 1.06$. Duplex findings before the start of treatment are given in table-II. A total of $74.5 \%$ $(n=179)$ patients had primary varicoseveins, $17 \%(n=41)$ had recurrent varicosities after previous surgery.Deep vein reflex was present in $8.3 \%(n=20)$ patients with patent deep veins. ABPIs was $>0.8$ in all cases. MeanUlcer healing time was 4.5 months (Range 3-24 months). The percentage of ulcer healing after each session of sclerotherapy is given in table-III.

The overall ulcer healing at 04 weeks was $83 \%$ and $95.4 \%$ after 08 weeks of the start of treatment with foam sclerotherapy.In 168 cases, all superficialreflex was successfully abolished afteronly one course of UGFS and remained so 
till the end of the study period. Seventeen patients had another treatment session. Rest required another one or two treatment sessions for residual/recurrent (recanalisation) or new varicosities during follow-up.

Incomplete healing occurred after four months, in 11 patients having a previous history of venous surgery/deepvein thrombosis/ extensive perforator disease/poor compliance to compression stockings. There was recurrence of the ulcer in $2.9 \%(n=7)$ patients treated with foam sclerotherapy and had their ulcers healed initially. The mean recurrent ulcer-free period was 24 weeks. In the author's opinion, this recurrence was due to the discontinuation of compression stockings or the formation of new incompetent perforators. No immediateor delayed deep vein thrombosis, pulmonary embolism, or visual disturbance occurred in our patients.

Table-I: Demographic data.

\begin{tabular}{|c|c|c|}
\hline \multicolumn{2}{|c|}{ Characteristics } & n (\%) \\
\hline \multirow{2}{*}{ Gender } & Male & $116(48.3 \%)$ \\
\cline { 2 - 3 } & Female & $124(51.7 \%)$ \\
\hline \multicolumn{2}{|c|}{ Ratio (Male: Female) } & $1: 1.06$ \\
\hline \multicolumn{2}{|c|}{ Age (Mean \pm SD) } & $34 \pm 08$ \\
\hline \multicolumn{2}{|c|}{$\begin{array}{c}\text { Previous DVT with } \\
\text { recanalized veins }\end{array}$} & $20(8.3 \%)$ \\
\hline \multirow{2}{*}{ Limb involved } & Right & $110(45.83 \%)$ \\
\cline { 2 - 3 } & Left & $130(54.16 \%)$ \\
\hline
\end{tabular}

There was no statistical difference in ulcer healing rate at 4 and 8 weeks in comparing the two groups. However, it is worth noting that statistically significant female patients healed with one and two sclerotherapy sessions. Male patients required more than 2 sessions, which was also significant compared to the female group (Table -IV).

\section{Table-II:Pretreatment duplex findings n(\%).}

\begin{tabular}{|c|c|}
\hline Characteristics & n (\%) \\
\hline Primary varicose veins & $179(74.58 \%)$ \\
\hline Recurrent varicose veins & $41(17.08 \%)$ \\
\hline Secondary varicose veins & $20(8.33 \%)$ \\
\hline \multicolumn{2}{|c|}{ Veins involved in duplex } \\
\hline $\begin{array}{c}\text { Great saphenous vein } \\
\text { primary }\end{array}$ & $106(44.16 \%)$ \\
\hline $\begin{array}{c}\text { Great saphenous vein } \\
\text { recurrent }\end{array}$ & $16(6.66 \%)$ \\
\hline $\begin{array}{c}\text { Small saphenous vein } \\
\text { primary }\end{array}$ & $47(19.58 \%)$ \\
\hline $\begin{array}{c}\text { Small saphenous vein } \\
\text { recurrent }\end{array}$ & $19(7.91 \%)$ \\
\hline Perforator veins primary & $25(10.41 \%)$ \\
\hline Perforator veins recurrent & $6(2.5 \%)$ \\
\hline
\end{tabular}

Table-III: Ulcer healing rates and sclerotherapy sessions.

\begin{tabular}{|c|c|}
\hline \multicolumn{2}{|c|}{ Results n (\%) } \\
\hline The ulcer healed within 04 weeks of the start of treatment & $199(83 \%)$ \\
\hline Total Ulcers healed within 08 weeks of the start of treatment & $227(95.4 \%)$ \\
\hline Ulcers healed after the first session of ultrasound-guided foam sclerotherapy & $168(70 \%)$ \\
\hline Ulcers needed a 2nd session of ultrasound-guided foam sclerotherapy & $17(7.08 \%)$ \\
\hline Ulcers needed 3rd and 4rth session of ultrasound-guided foam sclerotherapy & $44(18.33 \%)$ \\
\hline Non healed ulcers after 4months of treatment & $11(4.58 \%)$ \\
\hline Recurrent ulcers which remained healed for 02 weeks then recur & $07(2.92 \%)$ \\
\hline
\end{tabular}


Table-IV: Comparison between Male and female groups in terms of risk factors, ulcer healing, and sclerotherapy sessions.

\begin{tabular}{|c|c|c|c|}
\hline \multicolumn{4}{|c|}{ Results n (\%) } \\
\hline Variables & Male & Female & p-value \\
\hline Age & 36 & 29 & 0.07 \\
\hline Previous DVT & 15 & 5 & 0.001 \\
\hline Primary varicose veins & 79 & 100 & 0.08 \\
\hline Recurrent veins & 31 & 10 & 0.02 \\
\hline Secondary Varicose veins & 6 & 14 & 0.058 \\
\hline \multicolumn{4}{|c|}{ Ulcer healing rates: } \\
\hline Within 4 weeks & 94 & 105 & 0.091 \\
\hline Within 8 weeks & 103 & 124 & 0.061 \\
\hline \multicolumn{4}{|c|}{ Sclerotherapy sessions required for complete ulcer healing: } \\
\hline One session only & 68 & 100 & 0.002 \\
\hline Two sessions & 2 & 15 & 0.001 \\
\hline More than 2 sessions & 35 & 9 & 0.0039 \\
\hline Non healed ulcer & 10 & 1 & 0.0053 \\
\hline
\end{tabular}

\section{DISCUSSION:}

Superficial and deepvenous reflux leads to venous insufficiency and venous hypertension in chronically affected limbs, leadingto chronic venous ulceration. Traditional treatment of varicose veins is surgery. Most patients with chronic venous ulcers are frail and old, so not fit for surgery. New techniques (RFA,EVLA, and UGFS) are now under practice to treatthis condition $^{[7]}$. Wehad treated 240 patients having active chronic venous ulcers in our study with UGFS and compression for eradication of superficial venous reflex. Our healing rate at 18 monthsis comparable with the results of the ESCHAR trial $(40 \%)^{[8]}$. Most of the studies reported are of short duration ${ }^{[9,10]}$. Theulcer healing was $96 \%$ at 24 weeks, and recurrence $(7.1 \%)$ at 1 year has been reported in a study of twenty-seven patients treated with UGFS ${ }^{[9]}$ by Cabrera et al. showed $83 \%$ healing rate in 151 casesat 24 weeks and recurrence rate of $6.3 \%$ at 24 weeks in his study ${ }^{[11]}$.

Bergan et al. demonstrated that only $46 \%$ of ulcerswere healed in patients where the only compression was applied compared to $100 \%$ healing where compression and sclerotherapy were performed ${ }^{[12]}$. In another study, where Hertzman used UGFS to treat 13 cases of nonhealing venous ulcers, healing took place in 11 cases after 14 days $^{[13]}$. Similarly, $\mathrm{O}^{\prime}$ Hare and Earnshaw showed healing in $77.2 \%$ of patients treated with compression alone compared to $94 \%$ healing with compression combined with sclerotherapy ${ }^{[10]}$.

Ulcers healing did not occur in eighteen cases in our study. Seven had a recurrence and 11 never healed.Deep venous insufficiencyon doppler ultrasound and longer duration of ulcers before UGFS, poor compliance to pressure bandage/ stockings and development of new superficial venous reflex, previous venous surgery, and extensive perforator diseasewere thefactors associated with nonhealing / recurrence ${ }^{[11,14]}$. All of our patients were advised to use compressionbandages/stockings during the treatment period. The healing rate in our study 
was highest in main superficial veins, high in main veins with perforator disease, and patients with previous venous surgery. It was relatively low in patients with only perforator disease. A randomized control study is needed to document whether UGFS with compression is better than compression alone. We have started such a study in our department from April 2020 onward.

UGFS can abolish superficial venous refluxin $90 \%$ of patients with only one session. Thistechnique is safe, clinically effective, inexpensive, and a good alternative to varicose vein surgery ${ }^{[15]}$.

Chronic venous insufficiency with active chronic venous ulcers needs compression stockings and intervention withregular follow-up both clinically and radiologically to allow re-treatment of recurrence ${ }^{[15]}$.

\section{CONCLUSION:}

UGFS combined with compression bandages/ stockings probably offers the best treatment option to eradicate all superficial venous reflux and chronic venous ulcers. It promises the highest healing and low recurrence rates. It issimple, safe, and effective in recurrent or new superficial venous reflux.

\section{ACKNOWLEDGEMENT:None}

CONFLICT OF INTEREST:All authors disclose

no conflict of interest.

\section{GARNT SUPPORT \& FINANCIAL}

DISCLOSURE:None

\section{REFERENCES:}

1. Wittens C, Davies AH, Bækgaard N, Broholm $\mathrm{R}$, Cavezzi A, Chastanet $\mathrm{S}$ et al. Editor's choice-management of chronic venous disease: clinical practice guidelines of the European Society for Vascular Surgery (ESVS). European Journal of Vascular and Endovascular Surgery. 2015;49(6):678-737.

2. Whiteley MS. Understanding Venous Reflux: The Cause of Varicoses Veins and Venous Leg Ulcers. Whiteley Pub. Limited.2011.

3. Zhang M, Qiu T, Bu X, Li X, Liang G, Zhang $H$, et al. A national survey on management of varicose veins in China. Journal of Vascular Surgery: Venous and Lymphatic Disorders. 2018;6(3):338-346.
4. Lal BK. Venous ulcers of the lower extremity: definition, epidemiology, and economic and social burdens. InSeminars in Vascular Surgery. 2015;28(1):3-5. Doi: 10.1053/j. semvascsurg.2015.05.002

5. Oliveira RD, Mazzucca AC, Pachito DV, Riera R, Baptista-Silva JC. Evidence for varicose vein treatment: an overview of systematic reviews. Sao Paulo Medical Journal. 2018;136(4):324-332. Doi:10.1590/15163180.2018 .0003240418

6. Saraiva SM. A qualidade de vidaapóstratamentocirúrgico das varizes dos membrosinferioresnosdoentessubmetidos a cirurgiaconvencional versus Cirurgia Minimamente Invasiva.2018. Available at: https://repositorio-aberto.up.pt/ bitstream/10216/114033/2/277433.pdf

7. Epstein D, Onida S, Bootun R, Ortega-Ortega M, Davies AH. Cost-effectiveness of current and emerging treatments of varicose veins. Value in Health. 2018;21(8):911-920.

8. Ran F, Shi Y, Qiao T, Shang T, Liu Z, Liu CJ. Comparison of foam sclerotherapy alone or combined with stripping of the great saphenous vein for treating varicose veins. Dermatologic Surgery. 2017;43(4):541-547.

9. Alder G, Lees T. Foam sclerotherapy. Phlebology. 2015;30(2_suppl):18-23. Doi.10.1177/0268355515589536

10. O'Hare JL, Earnshaw JJ. Randomised clinical trial of foam sclerotherapy for patients with a venous leg ulcer. European Journal of Vascular and Endovascular Surgery. 2010;39(4):495499.

11. Goldman MP, Weiss RA. Sclerotherapy E-Book: Treatment of Varicose and Telangiectatic Leg Veins (Expert Consult). Elsevier Health Sciences.2016.

12. Davies HO, Popplewell M, Darvall K, Bate G, Bradbury AW. A review of randomised controlled trials comparing ultrasoundguided foam sclerotherapy with endothermal ablation for the treatment of great saphenous varicose veins. Phlebology. 2016;31(4):234240.Doi: $10.1177 / 0268355515595194$

13. Kemp N. A synopsis of current international guidelines and new modalities for the treatment of varicose veins. Australian Family Physician. 2017;46(4):229-233. 
Doi:10.3316/informit.741963359261459

14. Howard JK, Slim FJ, Wakely MC, Emerson LG, Davies CE, Kulkarni SR et al. Recanalisation and ulcer recurrence rates following ultrasound-guided foam sclerotherapy. Phlebology. 2016;31(7):506-513.

15. Bradbury AW, Bate G, Pang K, Darvall KA, Adam DJ. Ultrasound-guided foam sclerotherapy is a safe and clinically effective treatment for superficial venous reflux. Journal of Vascular Surgery. 2010;52(4):939-945.

\section{Author's Contribution:}

Muhammad Jamil: Data collection, article writing, data organization and data analysis. Rashid Usman: Correction and revision. Kishwar Ali: Correction and revision. AaizaAman: Drafting and editing. Rai Ahmad Khan Kharl: Reference collection.

Submitted for Publication: 28-07-2020 Accepted after revision: 05-04-2021 